\title{
Testicular migration, spermatogenesis, temperature regulation and environment of the sheath-tail bat, Taphozous georgianus
}

\author{
S. E. Jolly and A. W. Blackshaw \\ Department of Physiology and Pharmacology, University of Queensland, St Lucia, \\ Queensland 4067, Australia
}

\begin{abstract}
Summary. The testes of the common sheath-tail bat of tropical Australia undergo a seasonal migration between the abdomen and the scrotal pouches, while each cauda epididymidis is permanently maintained in the scrotal pouch. Straps of smooth muscle attach to both the cranial and caudal poles of the testes, and these extend cranially to the diaphragm and caudally to the cauda epididymidis. The testicular arteries are not coiled. Among the environmental factors investigated, maximum temperature correlated most significantly with testicular descent, and the number of spermatogonia per bat also correlated most significantly with maximum temperature. Body temperature of a captive bat ranged from 25 to $38^{\circ} \mathrm{C}$ and this was closely related to body weight and ambient temperature. It seems likely that the scrotal pouch provides a temperature slightly below that of the body and so facilitates sperm storage in the permanently scrotal cauda epididymidis. Migration of the testes probably serves to ameliorate the seasonal temperature fluctuations to which they are exposed while the relatively high correlation between maximum environmental temperature and spermatogonial numbers suggests that temperature may be a proximate influence on reproduction in the sheath-tail bat.
\end{abstract}

Keywords: testicular migration; spermatogenesis; temperature regulation; sheath-tail bat

\section{Introduction}

The teleology of scrotal evolution has been debated for many years and still remains one of the great unresolved mysteries of biology. Earlier theories on the functional significance of the mammalian scrotum centred on spermatogenesis and its apparent need for the reduced temperatures supplied by the scrotum (see Cowles, 1965). More recently, attention has turned to the epididymis, and Bedford (1977, 1978a) suggested that the requirements of the cauda epididymidis may have been the driving force behind scrotal evolution and that spermatogenesis had subsequently adapted to the cooler temperatures now prevailing in the testes.

Many insights into the functional significance of the scrotum have been gained by the study of ascrotal mammals, and within this group there is a wide range of patterns depending on the degree of testicular descent and the distance by which the cauda epididymidis precedes the descending testis (Carrick \& Setchell, 1977). In the majority of mammals the testes and epididymides migrate to their final position soon after birth, but in some species there is a seasonal testicular migration with the testes and epididymides descending into the scrotum only for the duration of the breeding season. Such seasonal testicular migrations are seen in chiropterans (Krutzsch, 1955; Marshall \& Corbet, 1959; Krutzsch \& Crichton, 1987), insectivores (Marshall, 1911), rodents (Rasmussen, 1917; Moore et al., 1934), carnivores (Koudele, 1986) and primates (Ramakrishna \& Prasad, 1967). 
In all these animals the epididymis accompanies the testis on its annual descent, but Kitchener (1973) has described a novel pattern of testicular migration in the common sheath-tail bat of Australia, Taphozous georgianus. In this animal each cauda epididymidis is permanently located in a scrotal pouch at the base of the penis and the testes migrate from the abdomen to the scrotal pouches each summer.

A closer examination of the reproductive pattern of the sheath-tail bat was undertaken to clarify which factors might be involved in testicular migration and the control of spermatogenesis in this species. The common sheath-tail bat is an insectivore averaging $30 \mathrm{~g}$ in weight and living in shallow caves throughout tropical Australia. Spermatogenesis begins in early summer, peaks in autumn and declines with the onset of winter. Spermatozoa are stored in the cauda epididymidis throughout winter, with mating and fertilization occurring in spring (Jolly \& Blackshaw, 1987).

\section{Materials and Methods}

Collection of animals and monitoring wild weights. Between March 1985 and April 1987, 54 adult male bats were collected from caves near Springsure in central Queensland $\left(24^{\circ} \mathrm{S} 148^{\circ} \mathrm{E}\right)$. Collections of 3 individuals were made monthly in the first year and every 2 months in the second. To assess the seasonal variation in the body weight of free living bats a number of individuals were captured at the time of each collection and weighed to the nearest $0 \cdot 1 \mathrm{~g}$.

Anatomy and histology. Shortly after collection animals were anaesthetized and fixed by vascular perfusion as previously described (Jolly \& Blackshaw, 1987). The cauda epididymidis of the sheath-tail bat is always located at the base of the penis, and so the position of each testis is accurately described by the distance between the anterior limit of the caput epididymidis and the caudal limit of the cauda epididymidis. This distance (the epididymal length) was measured to the nearest $0.5 \mathrm{~mm}$ for each epididymis and the mean calculated for each bat. Histological processing and quantitative histological analyses have been described by Jolly \& Blackshaw (1987).

To visualize the testicular blood supply, several bats were perfused via the left ventricle with India ink and latex (Dunlop, Sydney, Australia) after fixation. The distribution of smooth muscle and collagenous fibres in the testicular attachments were demonstrated with Milligan trichrome stain (Humason, 1972).

Body temperature measurements. Body temperature was remotely monitored in one captive bat every hour for a period of 5 weeks. Measurements were made to the nearest $0.5^{\circ} \mathrm{C}$ by a radiotelemetric thermometer (Mini-mitter, Sunriver, OR, U.S.A.) glued to the back of the animal with a thermistor probe inserted subcutaneously between the scapulae. Temperature recordings from this site approximated rectal temperatures and the thermistor could be accommodated in this area with minimal discomfort to the animal. There is no interscapular brown fat in the sheath-tail bat and little subcutaneous white fat occurs between the scapulae.

The experimental animal had been maintained in captivity for 18 months before the start of the experiment and was allowed 2 weeks to adapt to the presence of the thermometer before recording began. For the duration of the experiments the bat was kept in a controlled environment room on a $12 \mathrm{~h}$ light:12 h dark photoperiod. It was maintained on a diet of minced baby mice throughout its captive life. Body weight was recorded daily.

In Exp. 1 the bat was kept at an ambient temperature of $25 \pm 1^{\circ} \mathrm{C}$ and, to enable measurements to be made over a range of body weights, food was supplied ad libitum for 1 week and then restricted to $2 \mathrm{~g}$ daily for the remainder of the experiment. In Exp. 2 the bat was maintained between 24 and $26 \mathrm{~g}$ in weight and subjected to an ambient temperature of $30 \pm 1^{\circ} \mathrm{C}$ for 1 week and $20 \pm 1^{\circ} \mathrm{C}$ for a 2 nd week.

Statistical analysis. Correlation coefficients were calculated to indicate the degree of association between environmental factors, testicular position and the abundance of spermatogonia, spermatocytes, round spermatids and spermatozoa in each bat.

The change in epididymal length and the abundance of germ cell types roughly followed sinusoidal curves with a period of 1 year. These curves were transformed to straight-line models by transforming the day of the year $(t)$ with the equation $\sin [2 . \pi .(t+c) / 365]$, where $c$ is a period of days dependent on the starting point of the sinusoidal curve. The least squares method was used to determine the line of best fit for each parameter, with a value of $c$ being chosen to minimize the error term. These models provided estimates of the times of the year testes were at their lowest point of descent and each germ cell type was most abundant. The correlation coefficients of these models provided indications of the strength of the annual periodicity in the data and were useful as bench-marks for the assessment of models based on environmental factors.

Environmental data. Temperature and rainfall data for the town of Springsure were provided by the Australian Bureau of Meteorology. Temperatures used in the regression analyses were the mean values of the maxima, minima and means in the 7 days preceding the collection of each bat. Rates of change of temperature were taken as half the difference between mean values 7-14 days before collection and mean values 7-14 days after collection.

Rainfalls used in the regression analyses were the amounts that had fallen in the 30 days preceding the collection of each bat. Daylength was taken as the time between sunrise and sunset at $24^{\circ} \mathrm{S}$ on the date of collection, these data 
being provided by the Sydney Observatory. Rates of change of daylength were taken as half the difference between the length of day 7 days before collection and the length of day 7 days after collection.

\section{Results}

\section{Anatomy}

The principal anatomical features are illustrated in Fig. 1. Each cauda epididymidis was always in a subcutaneous pouch close to the base of the penis, while the testes varied in position from within the parapenile pouches to a position several millimetres caudal to the kidneys. The length of each coiled epididymis varied accordingly and in this study ranged from 6 to $23 \mathrm{~mm}$. When both testes were in the abdomen, left and right testes were generally in a similar position, while if 1 testis was fully descended the other was frequently in the inguinal canal or at the abdominal entrance of the inguinal canal.

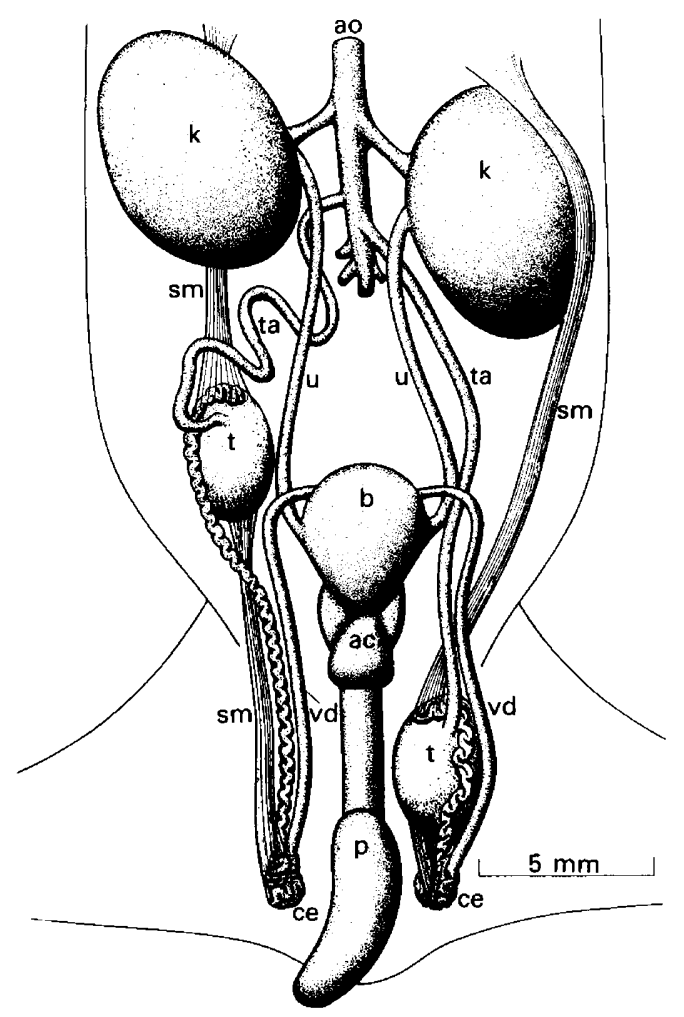

Fig. 1. The urogenital system of the male sheath-tail bat (ventral view) showing the left testis in the fully descended position and the right testis fully abdominal. $a c$, accessory gland complex; $a o$, aorta; $b$, bladder; $c e$, cauda epididymidis; $k$, kidney; $p$, penis; $s m$, smooth muscle; $t$, testis; $t a$, testicular artery; $u$, ureter; $v d$, vas deferens.

Examination of serial sections stained with Milligan trichrome stain revealed that the testes were suspended in a peritoneal fold with straps of smooth muscle attached to both cranial and caudal poles. The muscle running cranially attaches the testis to the diaphragm and may be analogous to the suspensory ligament of the fetal testis. The strap of smooth muscle extending 


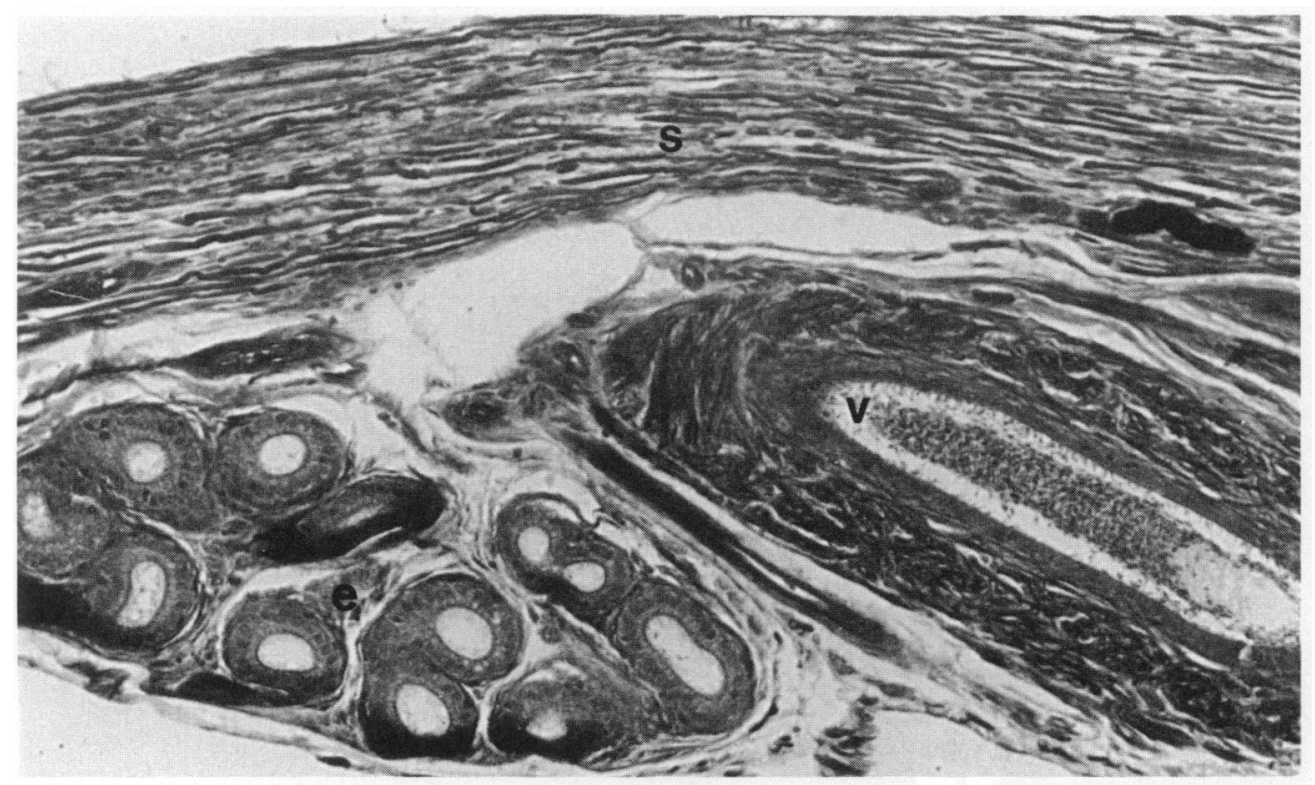

Fig. 2. Oblique section of the smooth muscle strap $(s)$ the corpus epididymidis $(e)$ and the vas deferens $(v)$ running between the testis and the scrotal sac. $\times 120$.

caudally (Fig. 2) would appear to be analogous to the gubernaculum and attaches the testis to the cauda epididymidis. Connective tissue invests the epididymis and firmly attaches the cauda epididymidis to the scrotal pouch and the caput epididymidis to the testis.

There is no pampiniform plexus and the testicular arteries are not coiled. These arteries are relatively straight when the testes are fully descended but follow a sinuous path when the testes are high in the abdomen.

\section{Testicular position}

The seasonal change in the position of the testes (as described by the epididymal length) is shown in Fig. 3. The sine curve model indicates that the testes were at their lowest point of descent in the first week of January each year ( $95 \%$ confidence interval \pm 12 days).

\section{Environmental data}

The monthly rainfall and the mean monthly maximum and minimum temperatures recorded at Springsure during the study period are shown in Fig. 4. The mean monthly rainfall recorded at Springsure in the period from 1977 to 1987 and the seasonal changes in daylength at Springsure are also shown in Fig. 4.

\section{Correlations}

Among the environmental factors investigated, epididymidal length showed the highest correlation with maximum temperature and the correlation coefficient for this model closely approached that obtained with the best fitting sinusoidal curve. The model based on daylength gave only a slightly poorer fit (Table 1). 


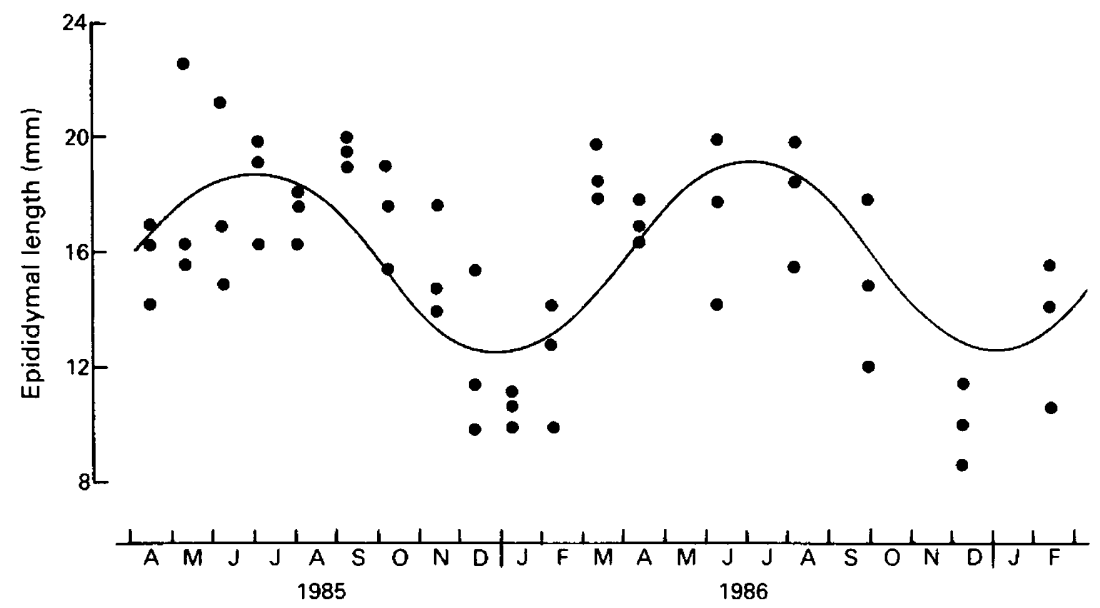

Fig. 3. Seasonal change in the position of the testes as described by the distance between the anterior limit of the caput epididymidis and the caudal limit of the cauda epididymidis $(r=0.69, t(52$ d.f. $)=6.8, P<0.001)$.
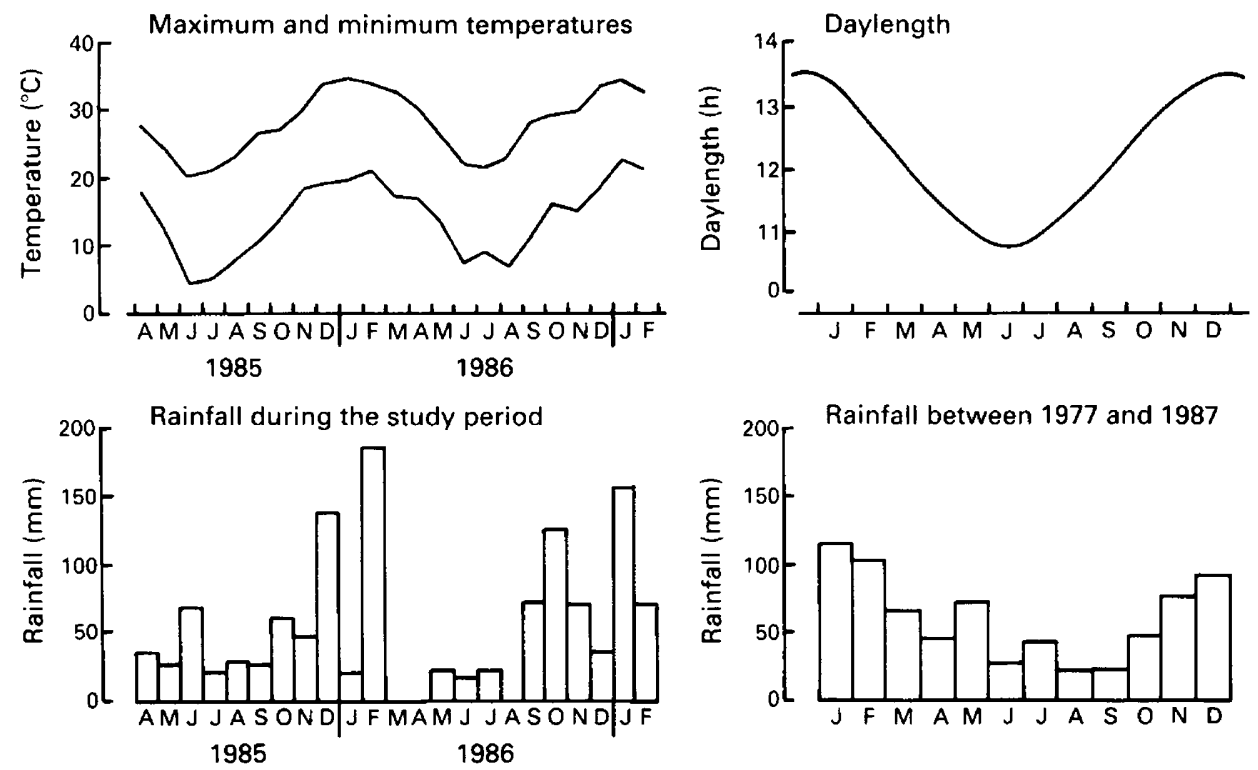

Fig. 4. Mean monthly maximum and minimum temperatures recorded at Springsure during the study period, seasonal changes in daylength at Springsure, monthly rainfall recorded at Springsure during the study period and mean monthly rainfall recorded at Springsure between 1977 and 1987.

There was a strong relationship between some histological characteristics and a number of environmental factors, and the strength of correlation between spermatogonial numbers and maximum temperature equalled that obtained with the best-fitting sinusoidal curve (Table 2).

\section{Body temperature}

The body temperature of the bat studied ranged from 25 to $38^{\circ} \mathrm{C}$ and depended on body weight (Fig. 5) and ambient temperature (Fig. 6). The diurnal changes in body temperature reflected the 
Table 1. Correlation coefficients and the values of $t$ for relationships between epididymal length and various environmental factors

\begin{tabular}{lrc}
\hline & $r$ & $t$ \\
\hline Annual periodicity & 0.69 & $6.8^{*}$ \\
Maximum temperature & -0.67 & $64^{*}$ \\
Mean temperature & -0.66 & $6.3^{*}$ \\
Minimum temperature & -0.63 & $5 \cdot 7^{*}$ \\
Daylength & -0.66 & $6.3^{*}$ \\
Rainfall in the preceding month & -0.53 & $4 \cdot 4^{*}$ \\
Rate of change of maximum temperature & -0.12 & 0.8 \\
Rate of change of daylength & 0.18 & 1.3 \\
\hline
\end{tabular}

${ }^{*} P<0.001$ (52 d.f.).

Table 2. Correlation coefficients for relationships between the number of spermatogonia, spermatocytes, round spermatids and spermatozoa per bat, and various environmental factors

\begin{tabular}{lcccc}
\hline & Spermatogonia & Spermatocytes & Spermatids & Spermatozoa \\
\hline Annual periodicity & $0.64^{*}$ & $0.75^{*}$ & $0.65^{*}$ & $0.62^{*}$ \\
Maximum temperature & $0.64^{*}$ & $0.57^{*}$ & $0.47^{*}$ & 0.26 \\
Minimum temperature & $0.56^{*}$ & $0.46^{*}$ & 0.37 & 0.17 \\
Daylength & $0.56^{*}$ & 0.34 & 0.25 & 0.03 \\
Rainfall & 0.19 & 0.16 & 0.08 & 0.07 \\
\hline
\end{tabular}

$* P<0.001$ (52 d.f.).
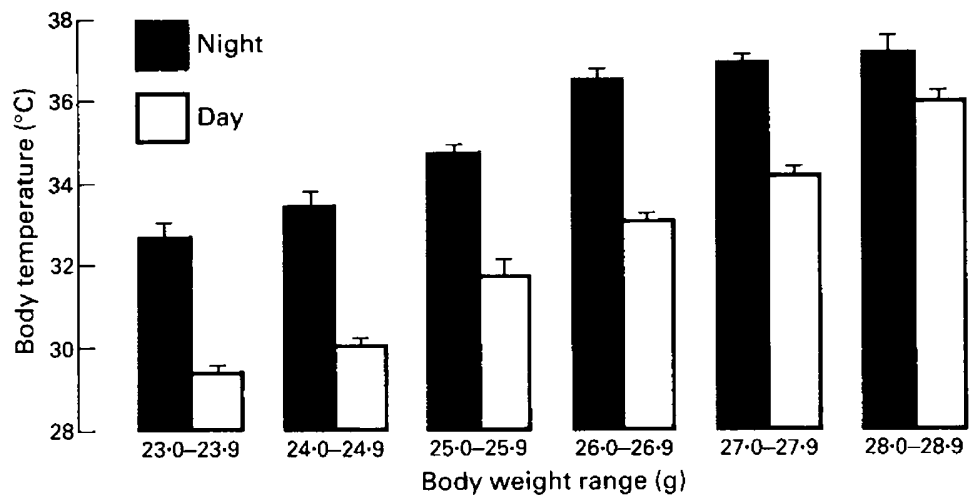

Fig. 5. Differences in day-time and night-time body temperatures ( \pm s.e.) of a sheath-tail bat in relation to body weight at an ambient temperature of $25^{\circ} \mathrm{C}$. 


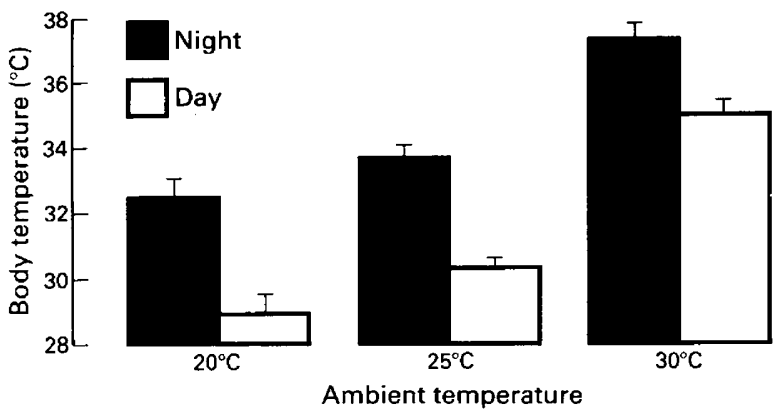

Fig. 6. Differences in day-time and night-time body temperatures $( \pm$ s.e. $)$ of a sheath-tail bat in relation to ambient temperature at a body weight between $24 \cdot 0$ and $25.9 \mathrm{~g}$.

activity cycle of the animal and night-time body temperatures averaged $3^{\circ} \mathrm{C}$ more than day-time body temperatures. Diurnal temperature differences were less when body temperatures were being maintained at the higher end of the range.

\section{Body weight}

The body weight of bats captured in the wild showed a marked seasonal variation (Fig. 7). Peak body weights were recorded in autumn of each year and declined sharply over winter.

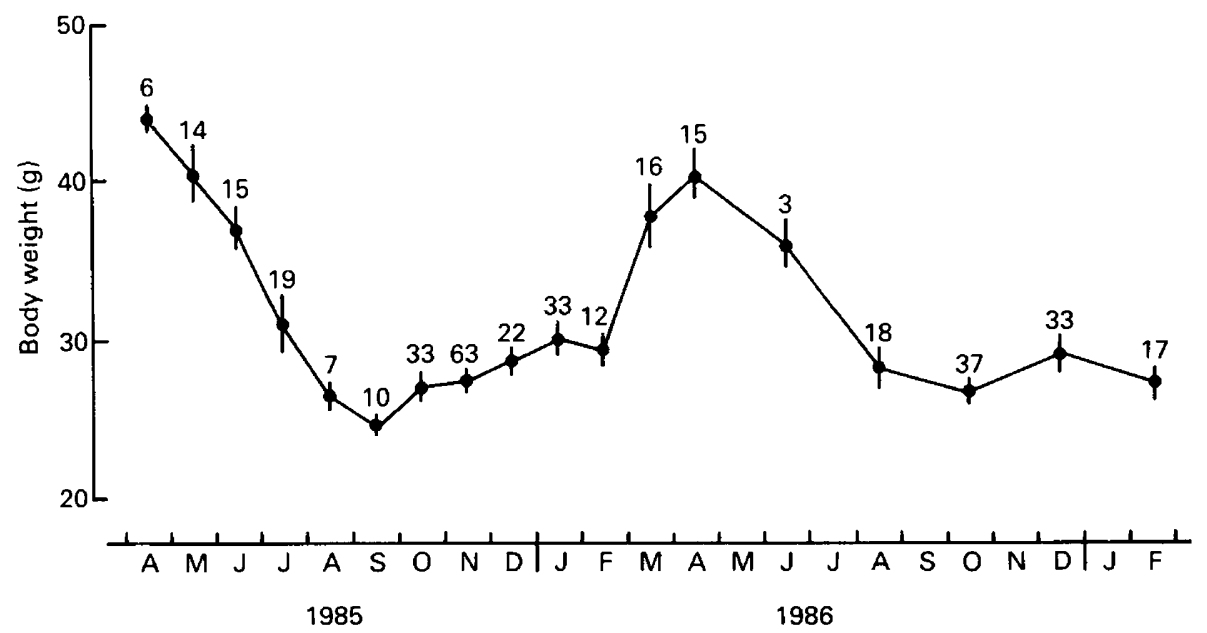

Fig. 7. Seasonal changes in the body weight of bats captured in the wild during the study period. The numbers indicate the number of bats measured and values are means \pm s.d.

\section{Discussion}

The sheath-tail bat stores spermatozoa in the cauda epididymidis over winter until mating in spring (Jolly \& Blackshaw, 1987). As lower epididymal temperatures facilitate the storage of spermatozoa (Bedford, 1978b; Foldesy \& Bedford, 1982; Rasweiler \& Bedford, 1982; Wong et al., 1982; Djakiew $\&$ Cardullo, 1986) it is clearly advantageous for the sheath-tail bat to maintain this organ as cool as possible. 
As the present study demonstrates, considerable reductions in body temperature might be expected over winter when environmental temperatures are reduced and the body weight of bats decline. A small amount of extra cooling of the epididymis may also result from the permanent maintenance of the cauda epididymidis in the scrotal pouch. In the musk shrew (Hasler \& Nalbandov, 1974) and the degu (Bedford et al., 1982) the testes reside in shallow coelomic evaginations and, despite the lack of vascular countercurrent heat-exchanging mechanisms, the testes are approximately $1.6^{\circ} \mathrm{C}$ below the temperature of the deep abdominal cavity.

Bernard (1985) reported that in the sperm storing Cape horseshoe bat each cauda epididymidis (but not the testes) migrated several millimetres caudally during the winter hibernation. Although body temperatures must be minimal at this time it would appear that even small reductions in cauda epididymal temperature are of some advantage.

If sperm storage is optimized by the permanent maintenance of the cauda epididymidis in the scrotal pouches, then why does the sheath-tail bat retain the seasonal migration of the testes? This migration may be an evolutionary remnant with no functional significance or, more likely, it provides a temperature-regulating mechanism for the testes. Enzyme systems within the testes have narrow temperature ranges in which they work most efficiently (Davis et al., 1963; Hall, 1965; Buyer \& Davis, 1966; LeVier \& Spaziane, 1968) and the regulation of testicular temperature by the dartos and cremaster muscles in scrotal mammals is well known.

It is likely that the large body temperature fluctuations observed in this study would prevent the precise regulation of intratesticular temperature in the sheath-tail bat, but ihere was a significant correlation between maximum environmental temperature and testicular position and testicular migration probably serves to ameliorate the seasonal temperature fluctuations to which the testes are exposed. Fowler \& Racey (1987) reported that the testicular temperature of the ascrotal European hedgehog is also regulated within a narrower range than body temperature although they did not speculate on how this was achieved.

The relatively high correlation between maximum temperature and spermatogonial numbers suggests that temperature may be a proximate influence on reproduction in the sheath-tail bat. Beasley \& Zucker (1984) reported that temperature was a more important influence than photoperiod on the reproductive cycle of pallid bats at certain times of the year, and Racey (1978) reported that the reproductive cycle of pipistrelle bats was unaffected by photoperiod. Captive sheath-tail bats have also failed to show reproductive responses to experimental photoperiod regimens (S. E. Jolly \& A. W. Blackshaw, unpublished). The shallow caves used by the sheath-tail bat offer protection from extreme diurnal temperature fluctuations while still being subject to seasonal temperature variations. It would seem likely that the temperature within these caves offers a reliable zeitgeber for the control of reproductive cycles.

If temperature does influence the reproductive cycle of the sheath-tail bat, this would explain why the species was reported to be continuously spermatogenic in a study including specimens from the northern tropics of Western Australia (Kitchener, 1973), while Jolly \& Blackshaw (1987) found that spermatogenesis ceased during winter at $24^{\circ} \mathrm{S}$.

We thank Les Hall for bringing the testicular migration in the sheath-tail bat to our attention, and Tony Barnes for suggesting the statistical approach taken in this paper.

\section{References}

Beasley, L.J. \& Zucker, I. (1984) Photoperiod influences the annual reproductive cycle of the male pallid bat (Antrozous pallidus). J. Reprod. Fert. 70, 567-573.

Bedford, J.M. (1977) Evolution of the scrotum: The epididymis as the prime mover? In Reproduction and Evolution, pp. 177-182. Eds J. H. Calaby \& C. H.
Tyndale-Biscoe. Australian Academy of Science, Canberra.

Bedford, J.M. (1978a) Anatomical evidence for the epididymis as the prime mover in the evolution of the scrotum. Am. J. Anat. 152, 483-508.

Bedford, J.M. (1978b) Influence of abdominal tempera- 
ture on epididymal function in the rat and rabbit. Am. J. Anat. 152, 509-522.

Bedford, J.M., Berrios, M. \& Dryden, G.I. (1982) Biology of the scrotum. IV. Testis location and temperature. J. exp. Zool. 224, 379-388.

Bernard, R.T.F. (1985) Reproduction in the Cape horseshoe bat (Rhinolophus capensis) from South Africa. $S$. Afr. J. Zool. 20, 129-135.

Buyer, R. \& Davis, J.R. (1966) Species variation in the effect of temperature on the incorporation of L-lysine-U-C ${ }^{14}$ into protein of testis slices. Comp. Biochem. Physiol. 17, 151-155.

Carrick, F.N. \& Setchell, B.P. (1977) The evolution of the scrotum. In Reproduction and Evolution, pp. 165-170. Eds J. H. Calaby \& C. H. Tyndale-Biscoe. Australian Academy of Science, Canberra.

Cowles, R.B. (1965) Hyperthermia, aspermia, mutation rates and evolution. Quart. Rev. Biol. 40, 341-367.

Davis, J.R., Firlit, F.F. \& Hollinger, M.A. (1963) Effects of temperature on incorporation of L-lysine-U-C ${ }^{14}$ in testicular proteins. Am. J. Physiol. 204, 696-698.

Djakiew, D. \& Cardullo, R. (1986) Lower temperature of the cauda epididymidis facilitates the storage of sperm by enhancing oxygen availability. Gamete Res. 15, 237-245.

Foldesy, R.G. \& Bedford, J.M. (1982) Biology of the scrotum. I. Temperature and androgen as determinants of the sperm storage capacity of the rat cauda epididymidis. Biol. Reprod. 26, 673-682.

Fowler, P.A. \& Racey, P.A. (1987) Relationship between body and testis temperatures in the European hedgehog, Erinaceous europaeus, during hibernation and sexual reactivation. J. Reprod. Fert. 81, 567-573.

Hall, P.F. (1965) Influence of temperature upon the biosynthesis of testosterone by rabbit testis in vitro. Endocrinology. 76, 396-402.

Hasler, M.J. \& Nalbandov, A.K. (1974) Body and peritesticular temperatures of musk shrews (Suncus murinus). J. Reprod. Fert. 36, 397-399.

Humason, G.L. (1972) Animal Tissue Techniques. W. H. Freeman \& Co., San Francisco.

Jolly, S.E. \& Blackshaw, A.W. (1987) Prolonged epididymal sperm storage, and the temporal dissociation of testicular and accessory gland activity in the common sheath-tail bat, Taphozous georgianus, of tropical Australia. J. Reprod. Fert. 81, 205-211.

Kitchener, D.J. (1973) Reproduction in the common sheath-tailed bat, Taphozous georgianus (Microchiroptera: Emballonuridae), in Western Australia. Aust. J. Zool. 21, 375-389.
Koudele, K.A., Napolitano, R.J. \& Aulerich, R.J. (1986) Inability to perceive photoperiod affects testes size and testosterone secretion in mink. Biol. Reprod. 34, Suppl. 1, 66, Abstr.

Krutzsch, P.H. (1955) Observations on the Mexican free-tailed bat, Tadarida mexicana. J. Mammal. 36, 236- 242 .

Krutzsch, P.H. \& Crichton, E.G. (1987) Reproductive biology of the male little mastiff bat, Mormopterus planiceps (Chiroptera: Molossidae), in southeast Australia. Am. J. Anat. 178, 353-368.

LeVier, R.R. \& Spaziane, E. (1968) The influence of temperature on steroidogenesis in the rat testis. $J$. exp. Zool. 169,113-120.

Marshall, A.J. \& Corbet, P.S. (1959) The breeding biology of equatorial vertebrates: reproduction of the bat Chaerephon hindei Thomas at latitude $0^{\circ} 26^{\prime} \mathrm{N}$. Proc. zool. Soc. Lond. 132, 607-616.

Marshall, F.H.A. (1911) The male generative cycle in the hedgehog; with experiments on the functional correlation between the essential \& the accessory sexual organs. J. Physiol., Lond. 43, 247-260.

Moore, C.R., Simmons, G.F., Wells, L.J., Zalesky, M. \& Nelson W.O. (1934) On the control of reproductive activity in an annual-breeding mammal (Citellus tridecemlineatus). Anat. Rec. 60, 279-289.

Racey, P.A. (1978) The effect of photoperiod on the initiation of spermatogenesis in pipistrelle bats, Pipistrellis pipistrellis. In Proc. 4th. Int. Bat Res. Conf., pp. 255-258. Eds R. J. Olembo, J. B. Castelino \& F. A. Mutere. Kenya National Academy of Arts and Sciences, Nairobi.

Ramakrishna, P.A. \& Prasad, M.R. (1967) Changes in the male reproductive organs of Loris tardigradus lydekkerianus (Cabera). Folia Primatol. 5, 176-189.

Rassmusen, A.T. (1917) Seasonal changes in interstitial cells of the testis in the woodchuck (Marmota monax). Am. J. Anat. 22, 475-515.

Rasweiler, J.J. \& Bedford, J.M. (1982) Biology of the scrotum. III. Effects of abdominal temperature upon the epithelial cells of the rat cauda epididymidis. Biol. Reprod. 26, 691-705.

Wong, R.G., Au, C.L. \& Bedford, J.M. (1982) Biology of the scrotum. II. Suppression by abdominal temperature of transepithelial ion and water transport in the cauda epididymidis. Biol. Reprod. 26, 683-689.

Received 8 February 1988 